\title{
The strategic role of the mass media in strengthening the discourse of moderation and rationality
}

\author{
Hussein Firoozi ${ }^{1}$, Fardin Mostafaye ${ }^{2, *}$, Mohamad Khaledian ${ }^{3}$ \\ ${ }^{1}$ National University of Yerevan, Yerevan, Armenia \\ 2Department of Social Communication Sciences, Payame Noor University, \\ PO BOX 19395 - 3697, Tehran, Iran \\ 32Department of Psychology, Payame Noor University, PO BOX 19395 - 3697, Tehran, Iran \\ *E-mail address: Fardin.Mostafaye@gmail.com
}

\begin{abstract}
This research is concerned with the role of the mass media in expanding the discourse of moderation. Mass media, as information highways, effective communication bridge on public thinking and civil society watchdog, contribute significantly to the process of informing and raising awareness to the people, strengthening cultural-thinking basics of the society and expanding the discourse of moderation. Mass media are the main leverages for education, campaigns, culture building, and constitution of public understanding. They are also, components for making civility. This research is descriptive-analytical and the analysis of research basics and theories indicate that mass media could by adopting different communication policies, play a strategic role in enhancing and expanding the discourse of rationality and moderation.
\end{abstract}

Keywords: Mass media; Discourse; Moderation; Public area; Cyber democracy

\section{INTRODUCTION}

In the view of modern politicians and strategists, modern governance is primarily mixed with rationality and prudence which are thought to be main aspects of moderation; finally, today after a century and a half endeavor, a state under the name of moderation is now formed in the country. This school of thought as a discourse or administrative strategy seeks to promote and further the national political history and social relations from extremism components in the book" Times" by Abdolhussein Zarinkoob, to a modern stage based on moderation, rationality, pragmatism and prudence; particularly, it proceeds to expose maturity of thinking discourses and new managerial approaches. Up to now, development discourse to accomplish economic development, reforms discourse to accomplish political development and fundamentalism discourse to accomplish distributional justice have found prominence. Moderation discourse, too, should delineate its objectives in proportion to the national situation and address modifying and establishing moderate policies whose materialization require discourse building and creation of a suitable thinking - cultural environment as well as social policy making. 
According to the role of mass media in expanding social communications, enhancing public areas, and discourse building, increasing information and citizens' awareness and influencing social relations, the present paper focuses on examining the role of mass media in strengthening and establishing the discourse on rationality and moderation in the society. It seems, as if, progress and quantitative and qualitative evolution of the "mass media" have deeply and irrevocably transformed the nature of symbolic production and exchange in the modern world.

The current century is named the "century of communications". In other words, due to the application of mass media whose expansion, influence and implications are on the rise, mass communications are found to be modernized, overshadowing the developments of the human societies. Today to stabilize, maintain and strengthen the cultural and political domination of the colonial powers, mass communications media are superior to the military forces and are considered strong and effective tools to capture identity and thoughts of public mindset. With the position mass media and communication means have found through the extra human life, they could be regarded as social entities and effective factors on the process of norms acceptance, and social values, sociability and norm orientation .People usually learn values, norms, beliefs, and behavioral orientations and theses from others and through the process of social education, sociability or in the course of socially institutionalized and transformed values. In this regard, because mass media deal directly and indirectly with peoples' sociability, they play a strategic and special role in this regard, identity building a discourse governing the society. Today, using the media in the framework of domestic and regional policies and international affairs are found to be important for promoting objectives in question and designing great powers' strategies. The extent to which new media are used includes communication satellites, large news corporations, press, various radio TV without the minimum cost and target the minds of the masses anywhere (Saeedi, 2011). Hence, the main research questions are raised as the following:

1. What role do mass media play in expanding moderation and rationality and establishing them?

2. What problem do the discourse of moderation and rationality encounter for expansion and establishment and what are the strategies recommended?

Thus, this research plans to analyze media functions in expanding the discourse of moderation based on various theories on public areas, school of Frankfurt, cyber democracy and cultural research.

Operational definition of concepts

Moderation

Moderation is meant recognition of varied and plural texture of the society. Moderation is awfulness, meritocratic, ethical and popular oriented. Moderation is a coordinated and consistent set of policies programs, choices and strategies that could sustainably and consistently respond to social claims and the needs of the society. It can make the government in a development oriented, strategist and policy making course. Discourse on moderation will achieve its objectives once it is changed to a discourse involving reasoning, recognition, thinking, cogitation and evident realities. As a political level and as a strategy by the government, a clear presentation of defining needs won't be probable except for introducing a transparent and explicit discussion respecting the definition of national interests .Moderation is defined when the goal of defining national interests is based on a free discussion procedure 
(Fazeli, 2013). There is no body more important than free media for setting behavior, thoughts and states' performance (Sareealghalam, 2013).

a) Challenges facing moderation: Complicated and inefficient bureaucracy, populism and absence of expertise, propaganda and gimmicks, extremism, imbalance in economic sectors, center-periphery, expectations and realities, oil and non oil products ,utilitarianism and realism, chasms and socio-moral problems are challenges and problems ahead of moderation.

b) Strategies: Influencing and establishing moderation and its positive implications have requisites in the society and it is imperative that moderation be promoted from a level of slogans to the levels of administrative -political pragmatism, expansion of the public areas, and efficiency in the economic and organizational areas.

Meantime, such components as valuation and political rationality, farsightedness and holistic approaches, an opening of media and academic space, effective ad targeted participation in the area of international affairs, meritocratic, extra factional activities, justice in distributing positions, participation and rational resources, improved economic situations, civil development, equilibrium, use of theories, disciplines and academicians, political understanding, restraint and respect for citizens' rights should be taken into account. Some other measures in this regard, should be considered; mechanisms of collective participation and popular networking should be enhanced, program - orientation and future programs as well as bureaucratic reforms should be seriously followed. Political rivalry should promote towards regularity and institutionalization.

Just information and wisdom should be transparently distributed. Result-oriented issues should be considered in reactions and strategies. National interests should come first than group interest and public economic diplomacy should be boosted. Establishing political and economic stability are of main requirements which requires a development of the discourse of moderation, exploration and delineating perspectives in relation with national capacities.

\section{DISCOURSE}

The term discourse is a category that has drawn the attention of theorists in the past decades and has found many applications in the area of politics, political sociology, cultural research and media. In its thinking and philosophical concepts, discourse is a Foucault concept. In Foucault's view, a group of episteme could constitute a discourse and this could eventually lead to producing authority in wide cultural and social networks. Discourse has various meanings. Some call it words, opinions and views. Publicly speaking, a unanimous definition of discourse by a majority of theoreticians is that which is said or written: including categories, subjects, and written or spoken material and that which relates to conversations, dialogues, exchange of views and debates. Dian Mc Dunell, in the book" Theories of discourse" believes dialogues to be preliminary terms of any discourse. Because, any speech, words or writing is considered a social process and has a social nature, thus, discourse, too, is a social phenomenon and has social grounds. In other words, spatial and temporal grounds, items of application, the way any user employs any material or proposition determine forms, types, and content of any discourse. The main purpose of building a discourse is to exert influence on popular thoughts, culture building, making social processes and authenticating values and subjects in question. 


\section{PUBLIC SPHERE}

Media as George Gorbner states is of prime importance in the society. The significance of publicization of mass media has resulted in the ability to publicize, define subjects provide terns and shared values of reference; utilize consideration and authority as well as widespread theoretical assistance. In all mass communication research, media have the prime role. Media organizations broadcast the messages that affect the social culture and this transforms mass media to part of established social forces (Littlejohnn, 2005). Einess and McLuhan consider mass media as the absence of civilization and both argue history is guided by dominant media at any time and Einess too maintains communication media are developed by human mind and initial interests of any historic era is some bigotry resulting from the dominant media. Hence, communication could be employed as a major means for materialization of vigilance and consciousness, organizing, policy making, and forming public thoughts. Thus, for communication to play such a duty, all entities involved in fulfilling these objectives should follow a harmonious and suitable communication methodology as well as a philosophical perspective (Mcluhan, 2007). An increasing growth of satellite and information networks along with their varied functions pave the way for public thinking of the societies (Khaneeki, 1997).

In today's world, mass media have assumed a major role via transforming new information and exchanging public thoughts and opinions on way to the advance of the human culture and civilization (Sarookhani, 1997). Based on theories by Lasswel, Charles Rights, Hobbes and Pascal and the media being dominant over latent and patent aspects of the society, are found to be totally fundamental and determinative in influencing the public thoughts.

\section{CYBER DEMOCRACY}

Some theorists referring to the extended communication among the citizens of the world through mass media, particularly the global internet network and the society becoming a network, believe communication will be a suitable ground for a new form of citizenship and democracy titled " Cyber democracy", "Tele democracy ", or "Electronic democracy" (Saeedi, 2007). Electronic democracy could be thought of as capacities in the IT sphere for enhancing the level of popular participation in the government. The internet, in fact, can strengthen a reciprocal relation between the state and the citizens; hence, it can affect the nature of democracy. Electronic democracy, in fact, indicates the quality of use and utility of the IT and communication under various strategies that overshadows various groups of people like states , officials, media, political organizations and citizens in political, social, economic and cultural sectors as well as in domestic and international areas (Sarafrazi and Memarzade, 2008). Today, impressive development has occurred in the technologies related to collection, production, and distribution of information. From now on, speaking of information explosion, communication revolution, and the effects of the media on the formation of the global public thoughts, particularly after the development of huge communication technology and in the end emergence of an information society look commonplace.

Cyber network, satellites, radio television stations and news agencies have challenged the structure of relations and international law. Increasing the possibility of citizens' and politicians' access to the information by the media, distribution of the information is thought to be the fundamental characteristics of these fundamental developments (Kharaziazar, 2005).

These issues will increase the ability of the citizens' digital literacy, establish grounds for the creation of a tele system or cyber democracy and increase the possibility of relations between nations and civilizations. This issue will also, provide collective participation for 
attaining an overall collective discourse including a discourse on moderation and rationality in the current circumstances.

\section{ROLE OF THE MEDIA IN EXPANDING THE DISCOURSE OF MODERATION AND RATIONALITY}

Increased political awareness, acquaintance with modern values, cultural - thinking pluralism, expansion of horizontal, transnational and multi lateral relations, citizens' participation, training of digital and meta cognitive citizens' public area enhancement, electronic trade growth, increased information exchange and dialogues could bring about a modern social formation. Based on different views including the Habemas' public sphere, school of Frankfurt, Cyber democracy, magic bullet, cultural studies and etc..., mass media has played a significant strategic role in expanding mass communication, facilitating the transfer of information and awareness, strengthening socio-political sociability processes, enhancing thinking - cultural concepts among the different states, building common values and terms, enhancing the public sphere, and enhancing knowledge - oriented development while use of satellite, media and internet programs could besides information and communication advantages, is a factor for disseminating and boosting discourse and strategies in question in societies and political pluralism and expanding democracy culture and values based on moderation and rationality .From theoretical basics of functional, cultural and liberalist perspectives, we can understand clear evidence by establishing the reality that media and the press in particular have been a ground for social growth and development in the course of democracy and creation of some public sphere.

Increased political awareness, acquaintance with modern values, cultural - thinking pluralism, expansion of horizontal, transnational and multi lateral relations, citizens' participation, training of digital and meta cognitive citizens' public area enhancement, electronic trade growth, increased information exchange and dialogues could bring about a modern social formation. Based on different views including the Habemas' public sphere, school of Frankfurt, Cyber democracy, magic bullet, cultural studies and etc..., mass media has played a significant strategic role in expanding mass communication, facilitating the transfer of information and awareness, strengthening socio-political sociability processes, enhancing thinking - cultural concepts among the different states, building common values and terms, enhancing the public sphere, and enhancing knowledge - oriented development while use of satellite, media and internet programs could besides information and communication advantages, is a factor for disseminating and boosting discourse and strategies in question in societies and political pluralism and expanding democracy culture and values based on moderation and rationality.

\section{FORMULATING AND PRESENTING STRATEGIES}

Media functions and policies have a prime role in civil and public development of the countries. Media, by adopting different communication policies, could aid the expansion of discourse and culture building, raising awareness and institutionalizing these components and finally influencing the values and nations' socio-cultural matters as well as international relations. In the course of establishing the favorable media effects in expanding the discourses on moderation and rationality, one can refer to the presentation of strategies in the direction like the following: 
- A prudent and organized use of the media and new communication technologies and other facilities of these sera for creating coexistence conditions among the civilizations, cultures and different races and ethnics.

- Persuading the media (the press, radio television, and also and modern media including news and social networks) to continue role play in the information society and disseminating the values and concepts in question.

- Media training and media literacy and establishing and expanding academic centers for cultural-media research

- While strengthening horizontal communication in the mass media, the national media should be transformed to a tool for the trilateral conversation among the state, nation and the elite and the possibility of public access to the modern information, dialogues and different analyses should also be provided.

- Media should equip masses to "rationality" so people will acquire some information and psychological features among and they will be directed towards a social development which is in line with the enhancement of identity component.

Influencing and establishing moderation and its positive implications have requisites in the society and it is imperative that moderation be promoted from a level of slogans to the levels of administrative - political pragmatism, expansion of the public areas, and efficiency in the economic and organizational areas.

Meantime, such components as valuation and political rationality, farsightedness and holistic approaches, an opening of media and academic space, effective ad targeted participation in the area of international affairs, meritocratic, extra factional activities, justice in distributing positions, participation and rational resources, improved economic situations, civil development, equilibrium, use of theories, disciplines and academicians, political understanding, restraint and respect for citizens' rights should be taken into account. Some other measures in this regard, should be considered; mechanisms of collective participation and popular networking should be enhanced, program - orientation and future programs as well as bureaucratic reforms should be seriously followed. Political rivalry should promote towards regularity and institutionalization.

\section{CONCLUSION}

Media have different political, security, social, cultural, and supranational functions and the expansion of the mass communication media is so great that the modern human could be thought of a media human and the new culture is considered a product of the communication means and propaganda.

\section{References}

[1] Little John S. (2005). Theory of communication. Tehran: Jungle publications.

[2] Sarookhani B. (1997). Sociology of communication. Tehran: Information.

[3] Sareealghalam M., Quarterly of Mehrname Humanities 30 (2013) 69-72. 
[4] Saeedi R. (2011). Investigating the international media coverage, Tehran: Khojaste publications.

[5] Saeedi R. (2007). Information society, Digital gaps, challenges and opportunities, Tehran: Khojaste publications.

[6] Sarafrazi M., Memarzade Gh. (2008). Mutual relations of the electronic state and electronic democracy (set of papers), the 2 th international conference of the electronic city, Tehran: Marjdanesh.

[7] Khaneeki H., Information and freedom of information, Journal of public relations, Tehran: Association of public affairs, 5 (1997) 30-33.

[8] Kharaziazar R. (2005). Cyber democracy; Strategy and techniques of diplomatic public relation $\mathrm{s}$ in the Cyber sphere, the first conference on the public electronic affairs.

[9] Fazeli M., Quarterly of Mehrname Humanities 30 (2013) 72-75.

[10] Mcluhan M. (2007). To understand the media. Tehran: Center for Research, Studies and measure TV and radio programs. 